\title{
Assessment of compliance with US Public Health Service Clinical Practice Guideline for tobacco by primary care physicians
}

\author{
Judy Kruger ${ }^{1 *}$, Alissa O'Halloran² and Abby Rosenthal ${ }^{1,3}$
}

\begin{abstract}
Background: The US Public Health Service Clinical Practice Guideline Treating Tobacco Use and Dependence: 2008 Update established an expanded standard of care, calling on physicians to consistently identify their patients who use tobacco and treat them using counseling and medication.

Findings: To assess compliance, we examined the extent to which physicians self-report following four of the five components of the 5A model: Ask about tobacco use, Advise patients who use tobacco to quit, Assist the patient in making a quit attempt, and Arrange for follow-up care. We used data from a Web-based panel survey administered to a convenience sample of 1,253 primary care providers (family/general practitioners, internists, and obstetrician/ gynecologists). We found that $97.1 \%$ of the providers reported that they consistently Asked and documented tobacco use, while $98.6 \%$ reported that they consistently Advised their patients to quit using tobacco. Among the family/general practitioners and internists, 98.3\% recommended "any" (medication, counseling, counseling and medication, telephone quitline) smoking cessation strategies (Assist). Among all providers, $48.0 \%$ reported that they consistently scheduled a follow-up visit (Arrange).
\end{abstract}

Conclusions: This study revealed that most primary care physicians reported that they Ask their patients about tobacco use, Advise them to quit, and Assist them in making a quit attempt, but only half reported that they Arrange a follow-up visit. Tobacco use screening and intervention are among the most effective clinical preventive services; thus, efforts to educate, encourage, and support primary care physicians to provide evidence-based treatments to their patients should be continued.

Keywords: Smoking cessation, USPHS Clinical Guideline, Tobacco, Primary care physicians, Health professionals

\section{Introduction}

Information on how physicians apply the 2008 US Public Health Service (USPHS) Clinical Practice Guideline recommendations on helping tobacco users quit can help facilitate the adoption of a brief intervention known as the 5A's: Ask, Advise, Assist, Arrange, and Assess [1]. Most smokers need to make multiple quit attempts before they quit [2], and only $7 \%$ of smokers who attempt to quit without any cessation assistance are successful [3];

\footnotetext{
*Correspondence: jkruger@cdc.gov

'Office on Smoking and Health, National Center for Chronic Disease Prevention and Health Promotion, Centers for Disease Control and Prevention, CDC4770 Buford Highway, Chamblee, Building 107, M/S, F-79, Atlanta, GA 30341-3717, USA

Full list of author information is available at the end of the article
}

thus, primary care providers must address cessation repeatedly with their patients who use tobacco [4].

Findings from the International Agency for Research on Cancer concluded that while population-level interventions have proven far more effective than individualbased interventions, brief advice from physicians to quit smoking is effective in comparison to other individually focused interventions [5]. The USPHS Guideline concluded that the provision of both medication support and counseling by physicians can increase the probability of quitting by $30 \%$ compared to medication alone [1]. Since about $70 \%$ of adult smokers visit a physician each year, physicians have many opportunities to help their patients who use tobacco by using counseling and medication [6]. 
Medicare, many state programs, and, more recently, Medicaid have expanded coverage of cessation treatments [7]. Provisions in the 2010 Affordable Care Act have expanded private and Medicaid cessation coverage. As of September 23, 2010, non-grandfathered private plans were required to cover, without cost-sharing, preventive services that have an " $\mathrm{A}$ " or " $\mathrm{B}$ " recommendation from the US Preventive Services Task Force, including tobacco cessation interventions [8]. On May 2, 2014, the US Departments of Health and Human Services, Labor, and the Treasury jointly issued subregulatory guidance on implementing this requirement [9]. The number of physicians who implement the USPHS Guideline may increase as knowledge of the requirement expands [10]. Monitoring implementation of the key tobacco cessation treatment recommendations is important, given the expansion of coverage for cessation counseling and medication and because of the potential increase in the number of smokers who visit a physician annually [11].

Multiple studies have assessed the prevalence of patientreported receipt of various components of the $5 \mathrm{~A}$ model; however, there is little physician-reported evidence on the extent to which they provide these services to patients $[12,13]$. We analyzed data from the 2011 DocStyles survey to determine the percentage of primary care providers who report providing four of the five components of the 5A's: Ask, Advise, Assist, and Arrange; the dataset did not allow examination of the Assess component. We also estimated the percentage of providers who reported recommending both counseling and medication.

\section{Methods}

Data were obtained from the 2011 DocStyles, a Webbased panel survey administered to a convenience sample of health care providers. A random sample of eligible health providers was selected from the Epocrates Honors Panel, an opt-in, verified panel of over 190,000 medical practitioners [14]. This sample was drawn to match the American Medical Association's (AMA) master data file proportions for age, gender, and region. Electronic invitations included a link to the Web-based survey; providers were eligible to participate if they were practicing in the United States, were actively seeing patients, and had been practicing for at least 3 years. Other studies using DocStyles have reported details of the survey design and data collection procedures $[15,16]$.

We invited 4,097 health care providers to participate during July to August 2011; of these, 2,204 (62.8\%) completed the entire survey. Because we wanted to assess compliance with the USPHS Guideline, we excluded those who were not primary care providers; the final sample $(N=1,253)$ consisted of family/general practitioners, internists, and obstetrician/gynecologists. Compared to the AMA master file, respondents in our sample were disproportionately men and slightly younger in age, though there were no differences by US region (data not shown).

\section{Measures \\ USPHS Clinical Practice Guideline}

All primary care providers were asked four questions related to their tobacco treatment behaviors. Providers were asked if they consistently Asked their patients if they smoke, Advised them to quit, Assisted with quitting, and Arranged follow-up. There were no skip patterns, so all primary care providers were asked each question and, thus, a respondent could have answered No to the Ask question and Yes to the Advise question. Respondents could select multiple options for the Assist question.

\section{Demographic and physician practice characteristics}

Demographic characteristics included sex, age, and race/ ethnicity. Provider practice characteristics included primary care provider type (family/general practice, internal medicine, or obstetrics/gynecology), teaching privileges (yes or no), type of practice (individual private practice, group private practice, or hospital/clinic practice), years in practice, number of physicians in practice, and estimated number of patients seen per week.

\section{Analysis}

Data were analyzed using SAS-Callable SUDAAN 10 (RTI International, Research Triangle Park, NC). Descriptive statistics were calculated to determine the number of physicians who self-reported providing various components of the $5 \mathrm{~A}$ model to their patients. Point estimates and 95\% confidence intervals were calculated to examine specific Assist outcomes, including 1) providing coaching or counseling, 2) prescribing or recommending a tobacco cessation medication, 3) asking patients to call a tobacco quitline, 4) any of these, or 5) the combination of counseling and medication (the two core recommendations of the USPHS Guideline).

\section{Results}

Of these primary care physicians, $46.6 \%$ were family/general practitioners, $33.4 \%$ were internists, and $20.0 \%$ were obstetricians/gynecologists (Table 1). Most respondents were men and were 36-45 years of age, non-Hispanic white, and in a hospital-based clinic or individual practice. Approximately one third of the respondents were in practice $11-20$ years, were in a practice with $3-5$ other physicians, and saw about 76-100 patients per week.

Among the providers in this sample, 97.1\% reported that they Asked about smoking, 98.6\% Advised tobacco users to quit using tobacco products, $98.3 \%$ Assisted tobacco users to quit, and 48.0\% Arranged a follow-up visit (Table 2). The proportion of physicians who reported 
Table 1 Prevalence of demographic and practice characteristics of primary care provider sample-DocStyles survey, 2011

\begin{tabular}{|c|c|c|c|}
\hline Characteristics & $N^{a}$ & $\%$ & $95 \% \mathrm{Cl}$ \\
\hline \multicolumn{4}{|l|}{ Sex } \\
\hline Men & 883 & 70.5 & $67.9,73.0$ \\
\hline Women & 370 & 29.5 & $27.0,32.1$ \\
\hline \multicolumn{4}{|l|}{ Age } \\
\hline $26-35$ & 147 & 11.7 & $9.9,13.5$ \\
\hline $36-45$ & 541 & 43.2 & $40.4,45.9$ \\
\hline $46-55$ & 340 & 27.1 & $24.7,29.6$ \\
\hline$\geq 56$ & 225 & 18.0 & $15.8,20.1$ \\
\hline \multicolumn{4}{|l|}{ Race/ethnicity } \\
\hline Non-Hispanic white & 802 & 64.0 & $61.3,66.7$ \\
\hline Non-Hispanic black & 56 & 4.5 & $3.3,5.6$ \\
\hline Hispanic & 63 & 5.0 & $3.8,6.2$ \\
\hline Non-Hispanic other & 332 & 26.5 & $24.1,28.9$ \\
\hline \multicolumn{4}{|l|}{ Primary care provider type } \\
\hline Family/general practitioners & 584 & 46.6 & $43.8,49.4$ \\
\hline Internists & 418 & 33.4 & $30.7,36.0$ \\
\hline Obstetrician/gynecologists & 251 & 20.0 & $17.8,22.2$ \\
\hline \multicolumn{4}{|l|}{ Teaching privileges } \\
\hline Yes & 637 & 50.8 & $48.1,53.6$ \\
\hline No & 616 & 49.2 & $46.4,51.9$ \\
\hline \multicolumn{4}{|l|}{ Type of practice } \\
\hline Individual & 221 & 17.6 & $15.5,19.7$ \\
\hline Group & 812 & 64.8 & $62.2,67.4$ \\
\hline Hospital/clinic & 220 & 17.6 & $15.5,19.7$ \\
\hline \multicolumn{4}{|l|}{ Years in practice } \\
\hline$\leq 5$ & 109 & 8.7 & $7.1,10.3$ \\
\hline $6-10$ & 353 & 28.2 & $25.7,30.7$ \\
\hline $11-20$ & 472 & 37.7 & $35.0,40.4$ \\
\hline$\geq 21$ & 319 & 25.5 & $23.0,27.9$ \\
\hline \multicolumn{4}{|l|}{ Number of physicians in practice } \\
\hline $1-2$ & 316 & 25.2 & $22.8,27.6$ \\
\hline $3-5$ & 345 & 27.5 & $25.1,30.0$ \\
\hline $6-10$ & 247 & 19.7 & $17.5,21.9$ \\
\hline $11-25$ & 181 & 14.4 & $12.5,16.4$ \\
\hline$\geq 26$ & 164 & 13.1 & $11.2,15.0$ \\
\hline \multicolumn{4}{|l|}{ Number of patients per week } \\
\hline $1-75$ & 242 & 19.3 & $17.1,21.5$ \\
\hline $76-100$ & 479 & 38.2 & $35.5,40.9$ \\
\hline $101-150$ & 394 & 31.4 & $28.9,34.0$ \\
\hline$\geq 151$ & 138 & 11.0 & $9.3,12.7$ \\
\hline Total & 1,253 & - & - \\
\hline
\end{tabular}

Cl confidence interval.

${ }^{\text {a }}$ Total unweighted number of respondents. arranging for follow-up was higher among physicians aged 26-35 years of age than all other age groups, family practitioners and internists than OB/GYNs, physicians with teaching privileges than those without, those with less years of practice, and those who saw more patients per week.

Among the family/general practitioners and internists who Assisted by providing interventions to tobacco users, $92.7 \%$ prescribed or recommended a medication, 88.0\% recommended counseling, $84.5 \%$ recommended both counseling and medication, and $54.2 \%$ recommended using telephone quitlines.

\section{Discussion}

Our findings reveal that nearly all primary care providers reported that they consistently Asked their patients about tobacco use, Advised that their tobacco using patients quit, and Assisted tobacco using patients with "any" smoking cessation strategy. Fewer providers Arranged a followup visit with their patients to address tobacco use. A previous study found slightly lower estimates for provider self-reported delivery of Ask (95\%), Advise (95\%), Assess (91\%), Assist (87\%), and Arrange (17\%); these variations could be due to differences in survey methodology, the questions used on the questionnaires, or subgroup distribution [12].

Approximately half $(48 \%)$ of the primary care providers reported that they consistently Arranged a followup visit. Although this number was lower than that of the other $5 \mathrm{~A}$ indicators reported here, the question only asked about one specific way of fulfilling the Arrange requirement: scheduling a follow-up visit and patients not interested in quitting may not be candidates for followup visits that are required by the USPHS Guideline. Our study found that disparities were observed across provider characteristics; primary care providers who selfreported that they scheduled follow-up contact related to a quit attempt were more likely to be younger physicians, family practitioners and internists, those with teaching privileges, those $\leq 5$ years in practice, and those who reported seeing $\geq 151$ patients per week. Offering follow-up assistance to smokers who attempt to quit maximizes the impact of these interventions on cessation; however, it is important to acknowledge that to $\mathrm{Ar}$ range follow-up takes more time than merely to Ask about smoking status and may require coordinated efforts from health care professionals in each provider's office. Although not assessed as part of this study, telephone quitlines often provide a mechanism for follow-up that can optimize population coverage and health services used, promote community-based interventions, and develop partnerships with health care systems to support cessation and treatment [17]. Increasing primary care 
Table 2 Prevalence of primary care providers' advice practices toward quitting ${ }^{\text {a }}$-DocStyles survey, 2011

\begin{tabular}{|c|c|c|c|c|c|c|c|c|}
\hline \multirow[t]{3}{*}{ Characteristic } & \multirow{2}{*}{$\begin{array}{l}\text { Ask } \\
\text { Asked about } \\
\text { smoking }\end{array}$} & \multirow{2}{*}{$\begin{array}{l}\text { Advise } \\
\text { Advised to quit } \\
\text { using tobacco }\end{array}$} & \multicolumn{3}{|l|}{ Assist } & \multirow[b]{2}{*}{$\begin{array}{l}\text { Recommended } \\
\text { using telephone } \\
\text { quitlines }\end{array}$} & \multirow[b]{2}{*}{$\begin{array}{l}\text { Offered any } \\
\text { assistance }\end{array}$} & \multirow{2}{*}{$\begin{array}{l}\text { Arrange } \\
\text { Scheduled a } \\
\text { follow-up }\end{array}$} \\
\hline & & & $\begin{array}{l}\text { Prescribed or } \\
\text { recommended } \\
\text { medication }\end{array}$ & $\begin{array}{l}\text { Recommended } \\
\text { coaching or } \\
\text { counseling }\end{array}$ & $\begin{array}{l}\text { Recommended } \\
\text { coaching } \\
\text { or counseling } \\
\text { and medication }\end{array}$ & & & \\
\hline & $\%(95 \% \mathrm{Cl})$ & $\%(95 \% \mathrm{Cl})$ & $\%(95 \% \mathrm{Cl})$ & $\%(95 \% \mathrm{Cl})$ & $\%(95 \% \mathrm{Cl})$ & $\%(95 \% \mathrm{Cl})$ & $\%(95 \% \mathrm{Cl})$ & $\%(95 \% \mathrm{Cl})$ \\
\hline \multicolumn{9}{|l|}{ Sex } \\
\hline Men & $97.3(96.0,98.2)$ & $98.8(97.8,99.3)$ & $91.6(89.3,93.5)$ & $87.7(85.5,89.8)$ & $83.3(80.5,86.0)$ & $52.1(48.8,55.4)$ & $98.1(96.9,98.8)$ & $48.4(45.1,51.7)$ \\
\hline Women & $96.8(94.4,98.1)$ & $98.1(96.1,99.1)$ & $95.3(92.2,97.2)$ & $88.9(85.7,92.1)$ & $87.5(83.8,91.3)$ & $59.2(54.2,64.2)$ & $98.9(97.2,99.6)$ & $47.0(41.9,52.1)$ \\
\hline \multicolumn{9}{|l|}{ Age } \\
\hline $26-35$ & $98.6(94.7,99.7)$ & $98.6(94.7,99.7)$ & $91.7(85.6,95.3)$ & $91.8(86.2,95.3)$ & $84.8(78.7,91.0)$ & $69.4(61.9,76.8)$ & $99.3(95.3,99.9)$ & $61.2(53.3,69.1)$ \\
\hline $36-45$ & $98.0(96.4,98.9)$ & $98.3(96.8,99.1)$ & $92.5(89.6,94.6)$ & $88.7(86.1,91.4)$ & $84.5(81.2,87.9)$ & $52.3(48.1,56.5)$ & $98.3(96.8,99.1)$ & $48.8(44.6,53.0)$ \\
\hline $46-55$ & $95.9(93.2,97.5)$ & $99.1(97.3,99.7)$ & $92.8(89.0,95.4)$ & $89.1(85.8,92.4)$ & $85.7(81.4,89.9)$ & $53.8(48.5,59.1)$ & $99.7(97.9,100.0)$ & $43.5(38.3,48.8)$ \\
\hline$\geq 56$ & $96.0(92.5,97.9)$ & $98.2(95.4,99.3)$ & $93.9(89.1,96.7)$ & $82.2(77.2,87.2)$ & $82.4(76.6,88.2)$ & $49.3(42.8,55.9)$ & $95.6(91.9,97.6)$ & $44.0(37.5,50.5)$ \\
\hline \multicolumn{9}{|l|}{ Race/ethnicity } \\
\hline Non-Hispanic white & $97.0(95.6,98.0)$ & $98.5(97.4,99.1)$ & $94.4(92.3,96.0)$ & $88.7(86.5,90.8)$ & $87.2(84.6,89.9)$ & $53.5(50.0,56.9)$ & $98.5(97.4,99.1)$ & $44.8(41.3,48.2)$ \\
\hline Non-Hispanic black & $100.0(100.0,100.0)$ & $96.4(86.8,99.1)$ & $91.5(79.4,96.8)^{c}$ & $83.9(74.3,93.6)^{c}$ & $78.7(67.0,90.4)^{c}$ & $55.4(42.3,68.4)^{c}$ & $96.4(86.8,99.1)^{c}$ & $58.9(46.0,71.8)^{c}$ \\
\hline Hispanic & $96.8(88.2,99.2)$ & $98.4(89.6,99.8)$ & $93.6(82.0,97.9)^{c}$ & $92.1(82.3,96.7)^{c}$ & $87.2(77.7,96.8)^{c}$ & $42.9(30.6,55.1)^{c}$ & $98.4(89.6,99.8)^{c}$ & $65.1(53.3,76.9)^{c}$ \\
\hline Non-Hispanic other & $97.0(94.5,98.4)$ & $99.1(97.2,99.7)$ & $89.3(85.7,92.8)$ & $86.4(82.8,90.1)$ & $79.5(74.9,84.1)$ & $57.8(52.5,63.1)$ & $98.2(96.0,99.2)$ & $50.6(45.2,56.0)$ \\
\hline \multicolumn{9}{|l|}{ Primary care provider type } \\
\hline Family/general practitioners & $96.1(94.1,97.4)$ & $98.6(97.3,99.3)$ & $94.0(91.8,95.7)$ & $90.4(87.7,92.5)$ & $86.0(83.1,88.8)$ & $61.1(57.2,65.1)$ & $98.8(97.5,99.4)$ & $53.1(49.0,57.1)$ \\
\hline Internists & $98.1(96.2,99.0)$ & $98.8(97.2,99.5)$ & $90.9(87.7,93.3)^{d}$ & $90.0(86.7,92.5)$ & $82.5(78.9,86.2)^{d}$ & $50.5(45.7,55.3)$ & $99.0(97.5,99.6)$ & $56.0(51.2,60.7)$ \\
\hline Obstetrician/gynecologists & $98.0(95.3,99.2)$ & $98.0(95.3,99.2)$ & & $79.3(74.3,84.3)$ & & $44.2(38.1,50.4)$ & $96.0(92.8,97.8)$ & $22.7(17.5,27.9)$ \\
\hline \multicolumn{9}{|l|}{ Teaching privileges } \\
\hline Yes & $97.2(95.6,98.2)$ & $98.3(96.9,99.0)$ & $92.9(90.3,94.9)$ & $86.3(83.7,89.0)$ & $84.0(80.8,87.3)$ & $54.2(50.3,58.0)$ & $98.3(96.9,99.0)$ & $51.3(47.5,55.2)$ \\
\hline No & $97.1(95.4,98.2)$ & $98.9(97.6,99.5)$ & $92.5(89.9,94.5)$ & $89.8(87.4,92.2)$ & $85.0(81.9,88.1)$ & $54.2(50.3,58.2)$ & $98.4(97.0,99.1)$ & $44.5(40.6,48.4)$ \\
\hline \multicolumn{9}{|l|}{ Type of practice } \\
\hline Individual & $97.7(94.7,99.1)$ & $99.1(96.5,99.8)$ & $91.4(86.3,94.6)$ & $86.4(81.9,90.9)$ & $80.5(74.8,86.2)$ & $48.0(41.4,54.6)$ & $96.8(93.5,98.5)$ & $50.7(44.1,57.3)$ \\
\hline Group & $96.9(95.5,97.9)$ & $98.6(97.6,99.2)$ & $94.1(91.9,95.7)$ & $88.8(86.6,91.0)$ & $86.4(83.7,89.1)$ & $54.7(51.3,58.1)$ & $98.9(97.9,99.4)$ & $46.6(43.1,50.0)$ \\
\hline Hospital/clinic & $97.3(94.1,98.8)$ & $97.7(94.7,99.1)$ & $89.5(85.2,93.9)$ & $86.8(82.3,91.3)$ & $82.2(76.8,87.6)$ & $58.6(52.1,65.1)$ & $97.7(94.7,99.1)$ & $50.5(43.8,57.1)$ \\
\hline \multicolumn{9}{|l|}{ Years in practice } \\
\hline$\leq 5$ & $98.2(93.0,99.5)$ & $99.1(93.8,99.9)$ & $92.2(85.1,96.0)$ & $89.9(84.3,95.6)$ & $83.3(76.1,90.6)$ & $61.5(52.3,70.6)$ & $100.0(100.0,100.0)$ & $61.5(52.3,70.6)$ \\
\hline $6-10$ & $96.9(94.5,98.3)$ & $98.3(96.3,99.2)$ & $91.4(87.7,94.1)$ & $90.4(86.8,93.0)$ & $82.8(78.5,87.0)$ & $57.2(52.1,62.4)$ & $98.6(96.6,99.4)$ & $50.7(45.5,55.9)$ \\
\hline $11-20$ & $98.1(96.4,99.0)$ & $98.5(96.9,99.3)$ & $94.2(91.2,96.2)$ & $89.0(86.2,91.8)$ & $88.1(84.7,91.4)$ & $54.4(50.0,58.9)$ & $98.5(96.9,99.3)$ & $47.9(43.4,52.4)$ \\
\hline$\geq 21$ & $95.6(92.7,97.4)$ & $98.7(96.7,99.5)$ & $92.4(88.3,95.2)$ & $83.4(79.3,87.5)$ & $81.9(77.0,86.8)$ & $48.0(42.5,53.4)$ & $97.2(94.7,98.5)$ & $40.4(35.1,45.8)$ \\
\hline
\end{tabular}


Table 2 Prevalence of primary care providers' advice practices toward quitting ${ }^{\text {a }}$-DocStyles survey, 2011 (Continued)

Number of physicians in practice

\begin{tabular}{|c|c|c|c|c|c|c|c|c|}
\hline $1-2$ & $97.8(95.4,98.9)$ & $99.7(97.8,100.0)$ & $93.1(89.2,95.6)$ & $87.0(83.3,90.7)$ & $82.6(78.0,87.2)$ & $47.5(42.0,53.0)$ & $97.8(95.4,98.9)$ & $46.5(41.0,52.0)$ \\
\hline $3-5$ & $96.5(94.0,98.0)$ & $97.7(95.4,98.8)$ & $91.9(88.0,94.6)$ & $87.0(83.4,90.5)$ & $83.4(79.0,87.8)$ & $51.6(46.3,56.9)$ & $98.8(97.0,99.6)$ & $47.8(42.6,53.1)$ \\
\hline $6-10$ & $97.2(94.2,98.6)$ & $98.0(95.2,99.2)$ & $93.6(89.0,96.3)$ & $87.4(83.3,91.6)$ & $84.5(79.3,89.7)$ & $59.1(53.0,65.2)$ & $98.8(96.3,99.6)$ & $47.0(40.7,53.2)$ \\
\hline $11-25$ & $97.2(93.5,98.8)$ & $98.3(95.0,99.5)$ & $90.8(85.1,94.5)$ & $91.2(86.1,94.5)$ & $86.3(80.8,91.7)$ & $61.9(54.8,69.0)$ & $97.8(94.3,99.2)$ & $51.4(44.1,58.7)$ \\
\hline$\geq 26$ & $97.0(92.9,98.7)$ & $99.4(95.8,99.9)$ & $94.7(89.3,97.5)$ & $89.6(85.0,94.3)$ & $88.6(83.2,94.1)$ & $56.7(49.1,64.3)$ & $98.2(94.5,99.4)$ & $48.8(41.1,56.4)$ \\
\hline \multicolumn{9}{|c|}{ Number of patients per week } \\
\hline $1-75$ & $96.7(93.5,98.3)$ & $99.2(96.8,99.8)$ & $87.4(82.7,92.0)$ & $87.6(83.5,91.8)$ & $80.8(75.3,86.3)$ & $55.4(49.1,61.6)$ & $97.1(94.1,98.6)$ & $40.9(34.7,47.1)$ \\
\hline $76-100$ & $97.3(95.4,98.4)$ & $98.3(96.7,99.2)$ & $93.4(90.5,95.5)$ & $89.4(86.6,92.1)$ & $86.0(82.6,89.4)$ & $58.5(54.0,62.9)$ & $98.5(97.0,99.3)$ & $48.2(43.7,52.7)$ \\
\hline $101-150$ & $97.5(95.3,98.6)$ & $98.7(97.0,99.5)$ & $96.4(93.6,98.0)$ & $87.3(84.0,90.6)$ & $87.5(83.8,91.2)$ & $49.5(44.6,54.4)$ & $98.5(96.7,99.3)$ & $47.0(42.0,51.9)$ \\
\hline$\geq 151$ & $96.4(91.6,98.5)$ & $97.8(93.5,99.3)$ & $89.7(84.0,95.5)$ & $86.2(80.5,92.0)$ & $77.6(69.7,85.5)$ & $50.7(42.4,59.1)$ & $99.3(95.0,99.9)$ & $62.3(54.2,70.4)$ \\
\hline Total & $97.1(96.0,97.9)$ & $98.6(97.7,99.1)$ & $92.7(90.9,94.2)$ & $88.0(86.2,89.8)$ & $84.5(82.3,86.8)$ & $54.2(51.4,56.9)$ & $98.3(97.4,98.9)$ & $48.0(45.2,50.7)$ \\
\hline & 1,217 & 1,235 & 929 & 1,103 & 847 & 679 & 1,232 & 601 \\
\hline
\end{tabular}

Notes: Physicians were first asked the Advise question: "For tobacco users who visited you over the last year, did you consistently recommend they quit using tobacco?" They were next asked the Ask question: "For patients who visited you over the last year, did you consistently ask and document whether they use tobacco?" The third question was for the Assist component: "For tobacco users who visited you over the last year, did you consistently try to help them quit tobacco by doing any of the following..."; respondents could select all that applied from the possible options: 1) providing coaching or counseling, 2) prescribing or recommending a tobacco cessation medication, or 3) asking them to call a tobacco quitline. The final question asked of primary care providers was for the Arrange component: "For tobacco users who visited you over the last year, did you consistently schedule a follow-up visit to help them quit tobacco?".

Cl confidence interval.

${ }^{\text {a } Q u e s t i o n s ~ a s k e d ~ o f ~ t o b a c c o ~ u s e r s ~ w h o ~ v i s i t e d ~ h e a l t h ~ c a r e ~ p r o v i d e r ~ o v e r ~ t h e ~ l a s t ~ y e a r . ~}$

${ }^{\mathrm{b}}$ The sample size for Advise is greater than that for Ask because it was the first question asked of respondents.

IInterpretation may be limited as the sample size was $<50$.

dWe excluded obstetrician/gynecologists from the medication portion of the analysis because medication recommendations are not uniform across all populations (e.g., infants, children, and pregnant women). Calculations for prescribed or recommended medication, and recommended counseling and medication were obtained from 1,002 obstetrician/gynecologists. 
providers' training on how to overcome barriers to implementation is warranted.

The Assist step also is important. Our study found a high prevalence of self-reported Assist recommendations (98.3\% recommended medication, counseling, or telephone quitlines) compared to Conroy and colleagues' findings that $79 \%$ of providers recommended any of these strategies [12]. Because there are disparate elements of the Assist step, it often needs to be tailored to each patient. To help maintain adherence to the Assist component, providers can develop office systems to bring screening and cessation interventions into routine practice $[1,18]$ and communicate with patients using motivational interviewing techniques (e.g., express empathy, avoid arguing, support self-efficacy) $[1,19]$. The literature suggests that physicians can motivate patients who are not willing to make a quit attempt through enhanced communication skills [20-24].

The USPHS Guideline suggests that physicians recommend the use of counseling and medication as a combined intervention [1]. We found that $84.5 \%$ of family/ general practitioners and internists recommended this combination to tobacco users. To our knowledge, this is the first study to evaluate primary care providers' selfreported compliance with the guideline to Assist patients who use tobacco to quit. Because the combination of counseling and medication is more effective for smoking cessation than either counseling or medication alone, family/general practitioners and internists are encouraged to provide patients with both brief counseling and FDA-approved pharmacotherapies. Since these treatments are effective and now are available, every patient who uses tobacco should be offered, at least, brief cessation counseling, medication, and referrals $[21,25]$.

These findings should be verified to confirm that physicians are consistently identifying and treating their patients who use tobacco at the high self-report rates found in this study, and that they are using both counseling and medication. This could be done via post-visit patient surveys, chart audits, and direct or recorded observation.

There are several important limitations of these data. First, though DocStyles is an opt-in Web-based survey designed to match specialty breakdown of the AMA membership, findings may not be representative of all primary care providers in the United States. Second, questions relied on recall of the previous 12 months, and it is possible that providers' recall may not have accurately captured their behavior. Third, aspects of the 5A model questions may have caused discrepancies: 1) the dichotomous Yes/ No response to questions included the word "consistently," 2) the Assess component of the 5A model was not included in this study, and 3) the Arrange component only asked about follow-up visits and implied all tobacco users should always have such visits, which may have introduced response bias. Fourth, the survey did not address the full spectrum of the USPHS Guideline, which may limit how providers interpreted their provision of interventions. Fifth, survey responses were self-reported, which could lead to reporting bias; studies suggest that physicians may overestimate the extent to which they provide various components of the $5 \mathrm{~A}$ model to their patients [12].

These findings highlight high levels of self-reported compliance with most components of the $5 \mathrm{~A}$ model. Depending on how the Arrange question was interpreted by respondents, the $48 \%$ compliance response may suggest a need to increase efforts toward follow-up. Since the expanded standard of care using the evidence-based treatment recommended in the USPHS Guideline includes the combination of counseling and medication, efforts to educate, encourage, and support primary care physicians to provide these treatments should be continued.

\section{Competing interests}

The authors declare that they have no competing interests.

\section{Authors' contributions}

All authors have contributed to, reviewed, and approved the final manuscript. Specifically, JK conceived of the study, developed the analysis plan, and had primary responsibility for interpreting results and writing the manuscript. AO conducted the analyses, assisted with writing the manuscript, and reviewed prior to submission. AR helped conduct the literature search and assisted in writing sections of the manuscript. All authors read and approved the final version.

\section{Acknowledgements}

The findings and conclusions in this report are those of the authors and do not necessarily represent the official position of the Centers for Disease Control and Prevention. The authors thank Dr. Michael C. Fiore, Center for Tobacco Research and Intervention, University of Wisconsin School of Medicine and Public Health for providing technical assistance with the design of the questions and interpretation of findings.

\section{Funding}

There were no sources of funding provided for this study.

\section{Author details}

'Office on Smoking and Health, National Center for Chronic Disease Prevention and Health Promotion, Centers for Disease Control and Prevention, CDC4770 Buford Highway, Chamblee, Building 107, M/S, F-79, Atlanta, GA 30341-3717, USA. ${ }^{2}$ Contractor Support for NCCDPHP/NGIS, Office on Smoking and Health, National Center for Chronic Disease Prevention and Health Promotion, Centers for Disease Control and Prevention, Atlanta, GA 30341-3717, USA. ${ }^{3}$ Health Systems Consulting, Atlanta, GA 30341, USA.

Received: 22 July 2014 Accepted: 12 February 2015

Published online: 07 March 2015

\section{References}

1. Fiore MC, Jaen CR, Baker TB, the Guideline Panel. Treating tobacco use and dependence: 2008 update: Clinical Practice Guideline. Rockville, MD: US Department of Health and Human Services, Public Health Service; 2008. http://www.ahrq.gov/professionals/clinicians-providers/guidelinesrecommendations/tobacco/index.html.

2. Yankelovitch SH. Evidence of real-world effectiveness of quitting. N Engl J Med. 2002;347:087-1093.

3. Zhu SH, Melcer T, Sun J, Rosbrook B, Pierce JP. Smoking cessation with and without assistance: a population-based analysis. Am J Prev Med. 2000;18 (4):305-11. 
4. Hurt RD, Ebbert JO, Hays JT, McFadden DD. Treating tobacco dependence in a medical setting. CA Cancer J Clinic. 2009;59:314-26.

5. International Agency of Research on Cancer. IARC handbooks of cancer prevention. Tobacco control. Volume 14: Effectiveness of tax and price policies for tobacco control. Lyon, France. 2011. http://www.iarc.fr/en/ publications/pdfs-online/prev/handbook14/handbook14-0.pdf.

6. Centers for Disease Control and Prevention. Quitting smoking among adults_-United States. MMWR 2011. 2001-2010;60(44):1513-9.

7. Centers for Medicare and Medicaid Services. Medicare national coverage determinations manual, Chapter 1, Part 4 (Sections 200-310.1). Coverage determinations. http://www.cms.gov/manuals/downloads/ncd103c1_Part4.pdf.

8. Patient Protection and Affordable Care Act, Public Law 111-148, U.S. Statutes at Large 2010, 119:124

9. Internal Revenue Service. Affordable Care Act tax provisions. http://www.irs. gov/uac/Affordable-Care-Act-Tax-Provisions.

10. National Committee for Quality Assurance. The state of health care quality 2011: continuous improvement and the expansion of quality measurement. 2011. Pages 46-47. http://www.ncqa.org/Portals/0/SOHC-web1.pdf.

11. U.S. Department of Health and Human Services. The health consequences of smoking: 50 years of progress: a report of the Surgeon General. Atlanta, GA: U.S. Department of Health and Human Services, Centers for Disease Control and Prevention, National Center for Chronic Disease Prevention and Health Promotion, Office on Smoking and Health; 2014.

12. Conroy MB, Majchrzak NE, Silverman CB, Chang Y, Regan S, Schneider LI, et al. Measuring provider adherence to tobacco treatment guidelines: a comparison of electronic medical record review, patient survey, and provider survey. Nicotine \& Tob Res. 2005;7(Sup 1):S35-43.

13. Association of American Medical Colleges. Physician behavior and practice patterns related to smoking cessation: full report. 2007. Washington, DC. Pages 1-146. https://www.aamc.org/download/55438/data/.

14. Novelli P. DocStyles 2011: methods. Washington, DC: Porter Novelli; 2011

15. Kruger J, Trosclair A, Rosenthal A, Babb S, Rodes R. Physician advice on avoiding secondhand smoke exposure and referral for smoking cessation services. Tob Induc Dis. 2012;10(10):1-10.

16. Kruger J, Teplinskaya A, Fiore MC. Trends in US primary care provider patient advice against secondhand smoke exposure: 2008-2010. Intern J Clinical Med. 2012:3:243-50.

17. World Health Organization. Developing and improving national toll-free tobacco quit line services: a World Health Organization manual. Geneva, Switzerland: World Health Organization; 2011. http://whqlibdoc.who.int/ publications/2011/9789241502481_eng.pdf.

18. Fu SS, van Ryn M, Sherman SE, Burgess DJ, Noorbaloochi S, Clothier B, et al. Proactive tobacco treatment and population-level cessation. JAMA Intern Med. 2014;174(5):671-7. doi:10.1001/jamainternmed.2014.177.

19. Community Guide Task Force on Community Preventive Services. The guide to community preventive services: what works to promote health. Part 1 : changing risk behaviors and addressing environmental challenges. Tobacco [Chapter 1]. New York, NY: Oxford University Press; 2005. http://www. thecommunityguide.org/tobacco/tobacco.pdf.

20. O'Malley PG. On motivating patients. Arch Intern Med. 2012;172(4):309-10.

21. Cornuz J, Will C. Nonpharmacological smoking cessation interventions in clinical practice. Eur Respir Rev. 2008;17(110):187-91.

22. Centers for Disease Control and Prevention. Best practices for comprehensive tobacco control programs-2014. Atlanta: U.S. Department of Health and Human Services, Centers for Disease Control and Prevention, National Center for Chronic Disease Prevention and Health Promotion Office on Smoking and Health; 2014. http://cdc.gov/tobacco/ stateandcommunity/best_practices/index.htm.

23. Revell CC, Schroeder SA. Simplicity matters: using system-level changes to encourage clinician intervention in helping tobacco users quit. Nicotine Tob Res. 2005;7 Suppl 1:S67-9.

24. Curry SJ, Keller PA, Orleans CT, Fiore MC. The role of health care systems in increased tobacco cessation. Annu Rev Public Health. 2008;29:411-28.

25. U.S. Department of Health and Human Services. Ending the tobacco epidemic: a tobacco control strategic action plan for the US Department of Health and Human Services. Washington, DC: Office of the Assistant Secretary of Health; 2010. http://www.hhs.gov/ash/initiatives/tobacco/ tobaccostrategicplan2010.pdf.

\section{Submit your next manuscript to BioMed Central and take full advantage of:}

- Convenient online submission

- Thorough peer review

- No space constraints or color figure charges

- Immediate publication on acceptance

- Inclusion in PubMed, CAS, Scopus and Google Scholar

- Research which is freely available for redistribution

Submit your manuscript at www.biomedcentral.com/submit 